This is a postprint of:

Rijkenberg, M.J., Baar, H.J.W. de, Bakker, K., Gerringa, L.J.A., Keijzer, E., Laan, M., Middag, R., Ober, S., Ooijen, J. van, Ossebaar, S., Weerlee, E.M. van \& Smit, M. (2015).

"PRISTINE", a new high volume sampler for ultraclean sampling of trace metals and isotopes. Marine Chemistry, 177(part 3), 501-509

Published version: $\underline{\text { dx.doi.org/10.1016/i.marchem.2015.07.001 }}$

Link NIOZ Repository: $w$ ww.vliz.be/nl/imis?module=ref\&refid=251561

[Article begins on next page]

The NIOZ Repository gives free access to the digital collection of the work of the Royal Netherlands Institute for Sea Research. This archive is managed according to the principles of the Open Access Movement, and the Open Archive Initiative. Each publication should be cited to its original source - please use the reference as presented.

When using parts of, or whole publications in your own work, permission from the author(s) or copyright holder(s) is always needed. 


\title{
"PRISTINE", a new high volume sampler for ultraclean sampling of trace metals and
} isotopes

Micha J. A. Rijkenberg ${ }^{1 *}$, Hein J.W. de Baar ${ }^{1,2}$, Karel Bakker ${ }^{1}$, Loes J.A. Gerringa ${ }^{1}$, Edwin Keijzer $^{1}$, Martin Laan ${ }^{1}$, Patrick Laan ${ }^{1}$, Rob Middag ${ }^{1,3,4}$, Sven Ober ${ }^{1}$, Jan van Ooijen ${ }^{1}$, Sharyn Ossebaar $^{1}$, Evaline M. van Weerlee ${ }^{1}$, Marck G. Smit ${ }^{1 * *}$

${ }^{1}$ Royal Netherlands Institute for Sea Research, Isle of Texel, the Netherlands ${ }^{2}$ University of Groningen, Groningen, the Netherlands ${ }^{3}$ Ocean Sciences Department, University of California Santa Cruz, Santa Cruz 95064, USA ${ }^{4}$ Currently at: Department of Chemistry, University of Otago, Dunedin, Otago, New Zealand *Corresponding author: Micha Rijkenberg, Email: Micha.Rijkenberg@nioz.nl, all other authors in alphabetical order.

** Corresponding author for loan or purchasing of sampling system: Marck Smit, Email: Marck.Smit@ nioz.nl, +31222 369300

\begin{abstract}
Many trace elements like $\mathrm{Mn}, \mathrm{Fe}, \mathrm{Co}, \mathrm{Ni}, \mathrm{Cu}$ and $\mathrm{Zn}$ are essential for marine life, some trace elements are of concern as pollutants, e.g. $\mathrm{Pb}$ and $\mathrm{Hg}$, while others, together with a diverse array of isotopes, are used to assess modern-ocean processes and the role of the ocean in past climate change. GEOTRACES is an international program that aims to measure the distribution of trace elements and isotopes throughout the world oceans to improve our understanding of their marine biogeochemical cycles. To contribute to GEOTRACES a new
\end{abstract}


sampler system was developed at NIOZ allowing efficient sampling of large volumes of seawater under ultraclean conditions. The 24 "PRISTINE" samplers each with a volume of 24.4L are made of a high-purity polymer Polyvinylidene Fluoride (PVDF) and are opened and closed using a butterfly-valve closing mechanism. The samplers are mounted on an alltitanium frame and deployed using a poly-aramide hydrowire (Super Aram) with internal power/signal conductors. Upon recovery the complete frame is immediately placed in its own clean-air laboratory unit. Samplers are (i) always closed when onboard, (ii) always mounted on the frame without the need for hand-carrying heavy samplers, and (iii) can be deployed again with minimal (manual) preparation. The PRISTINE ultraclean sampling system was used for the first time during the GA02 GEOTRACES cruises in the West Atlantic Ocean (2010-2012). During 60 full ocean depth stations all 24 samplers closed with a 100\% success rate. Sampling proved to be much faster, less labor intensive, and ultraclean. A comparison of salinity, temperature, nutrient and oxygen data collected with the rectangular titanium frame with PRISTINE samplers and a traditional CTD frame with Niskin samplers showed that the CTD systems functioned equally well, that the PRISTINE samplers took discrete seawater samples without any inward leakage of seawater during the up-cast, and that no atmospheric oxygen contaminated the seawater samples in the PRISTINE samplers after return on deck. The excellent agreement between 13 trace elements sampled with PRISTINE and sampled during the cross over occupation of US-GEOTRACES at the Bermuda BATS site $\left(32^{\circ} \mathrm{N}\right.$, $64^{\circ} \mathrm{W}$ ) shows it suitability for ultraclean trace element and isotope sampling (see accompanying paper).

\section{Introduction}

Trace elements like $\mathrm{Mn}, \mathrm{Fe}, \mathrm{Co}, \mathrm{Ni}, \mathrm{Cu}$ and $\mathrm{Zn}$ are necessary constituents in many metabolic functions of marine organisms (de Baar and LaRoche, 2003; Morel and Price, 
2003). Other trace elements like for example $\mathrm{Pb}$ and $\mathrm{Hg}$ are toxic. Trace elements play key roles in ocean ecosystem functioning, biological production, and the biogeochemical cycles of nutrients and carbon. Therefore, to understand the Earth's system and how global climate change will affect this system, it is important to understand the marine biogeochemical cycles of these trace elements. In the sedimentary record, trace elements and their isotopes also form important tools to investigate environmental conditions and changes in the past. However, the large-scale oceanic distributions of these trace elements and isotopes in the modern oceans and the processes that govern their distributions are still poorly known.

The GEOTRACES project is an international project that aims to improve our understanding of biogeochemical cycles and large-scale distributions of trace elements and isotopes in the marine environment and establish the sensitivity of these distributions to changing environmental conditions (Henderson et al., 2007). The objective is to elucidate important biogeochemical processes, sources and sinks that determine the distributions of bioessential and other trace elements in the world oceans. Advances in clean sampling protocols and equipment as well as analytical techniques now allows for the high resolution sampling of a wide range of trace elements and isotopes along full depth transects across the world's oceans.

To contribute to GEOTRACES, a new sampler system "TITAN" was developed at NIOZ in 2005 allowing efficient sampling of seawater under ultraclean conditions (de Baar et al., 2008). A rectangular shaped all-titanium frame was developed and fitted with a CTD system in a titanium housing and 24 conventional newly purchased GO-FLO samplers of $12 \mathrm{~L}$ volume each. To guarantee trace metal clean sampling each GO-FLO sampler was coated internally with Teflon. The use of GO-FLO samplers (General Oceanics) made of PVC and internally coated with Teflon has been an accepted method for trace metal clean sampling ever since its first application more than 30 years ago (Bruland et al., 1979). To reduce the 
risk of contamination the GO-FLO samplers stayed closed while on board and only opened after deployment at $20 \mathrm{~m}$ depth. After recovery, the complete TITAN frame was immediately placed inside a clean-air laboratory unit for sub-sampling and remained there until its next deployment. This complete system has been used successfully during several cruises in the Arctic, Antarctic and Northeast Atlantic Ocean with a total of 113 full depth casts. The system proved clean to sample for dissolved Fe (Klunder et al., 2014), the organic complexation of Fe (Thuróczy et al., 2011), dissolved Al (Middag et al., 2009), dissolved Mn (Middag et al., 2013), dissolved Zn (Croot et al., 2011), the organic speciation of Zn (Baars and Croot, 2011), dissolved Cd (Baars et al., 2014) and the stable isotopes composition of dissolved Cd (Abouchami et al., 2011; Abouchami et al., 2014; Xue et al., 2013) and Zn (Zhao et al., 2014).

To allow the clean sampling of larger volumes of seawater for a whole suite of trace elements and their stable isotopes, a new sampler system was developed at NIOZ in 2010. The TITAN frame is now fitted with 24 "PRISTINE" samplers each with a volume of $24.4 \mathrm{~L}$. When designing the new PRISTINE samplers, all drawbacks from the existing GO-FLO samplers were dealt with and eliminated. The PRISTINE samplers are made from intrinsically clean PVDF whereas GO-FLO samplers are made of Teflon coated PVC. The PRISTINE samplers do not require an internal pre-cleaning step with dilute acid as sometimes performed with GO-FLO samplers. The PRISTINE samplers use a butterfly valve system allowing a large opening at the top and bottom whereas the GO-FLO bottle open and close using a small rotating ball-valve system. The butterfly valve system ensures better flushing, the secure and reliable closing of the samplers, and the use of a seawater filled hydraulic closure system versus stainless steel springs. Furthermore, the PRISTINE samplers have no dead spaces and can be fully drained, thus preventing any risk of missing any sedimented particulate fraction. Finally, the PRISTINE samplers can be prepared for deployment without handling them in less than 3 minutes, versus at least half an hour of full human contact labor with the GO-FLO 
bottles.

The TITAN frame fitted with the PRISTINE samplers has now been successfully used during 8 research cruises along the whole West Atlantic Ocean, in the Mediterranean Sea and the Black Sea, totaling over 130 full depth hydrocasts. In this article we present the PRISTINE samplers and use some of the data from the West Atlantic Ocean to show its suitability for large scale trace metal clean sampling of large volumes of seawater. An accompanying article shows in a more extensive way that this trace metal clean sampling system has been successfully involved in the intercomparison of a suite of 13 trace elements sampled during a cross-over station at BATS between the Dutch GA02 GEOTRACES cruise in 2010 and the US GA03 GEOTRACES cruise in 2011 (Middag et al., this issue).

\section{Materials and methods}

\section{The PRISTINE samplers}

\section{Materials of the PRISTINE sampler}

All metal parts of the PRISTINE samplers are made of unalloyed (pure) grade 2 Ti. The rationale for using Ti which is also used in the TITAN frame (de Baar et al., 2008) is that Ti is a relatively inert metal that withstands corrosion in the seawater environment. It is also relatively easy to shape $\mathrm{Ti}$ into custom-made products. We did consider graphite-epoxy (carbon fibre) as it is the least corrosive in the galvanic series, but this is only economical for production in series using costly molds. The use of metals like aluminum $(\mathrm{Al})$, chromium $(\mathrm{Cr})$, manganese $(\mathrm{Mn})$, iron $(\mathrm{Fe})$, cobalt $(\mathrm{Co})$, nickel $(\mathrm{Ni})$, copper $(\mathrm{Cu})$, zinc $(\mathrm{Zn})$, silver $(\mathrm{Ag})$, cadmium $(\mathrm{Cd})$, tin $(\mathrm{Sn})$, platinum $(\mathrm{Pt})$, mercury $(\mathrm{Hg})$ and lead $(\mathrm{Pb})$ was avoided as these are the metals we are interested in to measure in the marine environment and would therefore form a contamination risk. An external coating to separate the parts made of these metals from 
the seawater could be applied, however, coatings tend to get physical damage or cracks or invisible under the coating. Although Ti is also a trace element of interest in the oceans, it is shown that there is no detectable Ti contamination from the PRISTINE samplers or from the Titan frame (Middag et al., this issue).

The large volume PRISTINE samplers are made of the polymer Polyvinylidene Fluoride (PVDF). Ultra-high purity grade PVDF is produced in a clean room environment by Georg Fischer Piping Systems (Herzogenburg, Austria) and available under the commercial brand name SYGEF ${ }^{\circledR}$ Plus. Major customers are the semi-conductor and the pharmaceutical industry, both requiring high purity production processes. The PVDF is free of additives, pigments or stabilizers and has a white opaque appearance. We chose to use PVDF because low purity plastics contain almost all of the trace metals of interest as either impurities or sometimes intentionally as a catalyst or stabilizer in the production process. For example, $\mathrm{Cd}$ is used as a catalyst in many plastics and $\mathrm{Al}$ is sometimes used as a catalyst in the production of polyethylene, whereas Sn is used as a stabilizer in PVC. Coating low purity PVC with Teflon spray has been the practice for GO-FLO samplers or lever-action type Niskin or Niskin-X samplers. However, also here cracks or porosity in the coating may expose the underlying low purity PVC.

\section{Construction and operation of the PRISTINE sampler}

The samplers are designed in a way that once the sampler is closed, the seawater sample is only in contact with the high purity PVDF, the two flat silicone O-rings and the polytetrafluoroethylene (PTFE, Teflon) of the two small valves for draining (lower) and inlet (upper) of $\mathrm{N}_{2}$ gas. To construct the PRISTINE samplers, PVDF piping with a length of $1080 \mathrm{~mm}$, an external diameter of $180 \mathrm{~mm}$ and an internal diameter $162 \mathrm{~mm}$ was used (Figure 
1). PVDF sheets with a thickness of $60 \mathrm{~mm}$ were used to construct two end-pieces that were hot plate welded on both ends of the straight pipe, together forming the main body of the sampler (Figure 1). Note that each end-piece has an internal $135^{\circ}$ angle ring surface extending $7 \mathrm{~mm}$ inwards that serves as the resting surface for the round, flat silicone O-ring in the closing lid to completely seal the closed sampler (Figure 1). Furthermore, there are two external extensions (Figure 1). One extension is used to attach 2 titanium levers and the actuating cylinder used to drive the third central Ti lever. The second extension is to implement the small PTFE valve to drain the bottle for sample or pressurize the bottle with $\mathrm{N}_{2}$ gas. The bottom PTFE draining valve is positioned in such a way that the sampler can be completely drained. Furthermore, two PVDF mounting rings are fitted on the outside around the sampler body just above and just below the lower and upper end-pieces to fix the PRISTINE sampler to the titanium frame using Ti bolts.

The lids are also cut from $60 \mathrm{~mm}$ PVDF sheets. Each round lid has a groove around its circumference in which a flat sealing ring is placed which is cut from silicone elastomer (polysiloxane) (Figure 1). We chose a flat silicone ring because a flat ring adjusts to unconformities as small dents or imperfections in the roundness of the sampler body while still maintaining a reliable seal. The samplers are closed while on board and during deployment through the ocean surface. At 5-10 m depth the lids start to open automatically, using the outside water pressure as a driving force. Because the bottom lids on each sampler experience a 0.13 Bar higher pressure to open than the top lids, the bottom lids always open first. As water rushes in from below, the air inside the sampler compresses until it is in equilibrium with the local water pressure. This creates a relative overpressure of 0.055 Bar which pushes against the inside of the upper lid, thus preventing it from opening. A vent valve in the rectangular extension block on the top lid operated by the titanium lever vents off this air (Figure 2), after which the upper lids also open. 
The expansion of the sampled trapped water when ascending in the water column results in an overpressure of approximately $0.5-1$ Bar. At that point the internal overpressure in the sampler is enough to open the top lid over-pressure valve and release pressure by allowing water to leave the sampler (Figure 2). The overpressure of 0.5-1 Bar also pushes both lids outwards by some $3 \mathrm{~mm}$ into what becomes their final positions against the $135^{\circ}$ ring surface of the end-piece. On the outside of the lid, a rectangular $25 \mathrm{~mm}$ high and $20 \mathrm{~mm}$ thick extension block is fitted, to which 3 Ti levers are attached using small Ti pivoting rods (Figure 2). The central Ti lever contains a slit to allow the lever to bend under tension (Figure 2). This built in spring action of the lever serves both to facilitate the $3 \mathrm{~mm}$ displacement of the lids while moving into their final positions and meanwhile to still keep exerting an outward pulling force on these lids. On the other end, the Ti levers are connected to two PVDF actuating cylinders mounted on the outside of the top and bottom of the sampler. These cylinders are part of the hydraulic system used to open and close the samplers (Figure 2). The central $\mathrm{Ti}$ lever connects via a Ti vertical rod to the piston in the actuating cylinder. The overall configuration allows the valve lid to completely open under a $90^{\circ}$ angle. Taking into account (i) the cross-sectional surface area of the open lid, (ii) the 3 titanium levers attached to the extension block, (iii) the top lid over-pressure valve, and (iv) the $7 \mathrm{~mm}$ width of the $135^{\circ}$ angled ring, the top and bottom plane of the samplers are $78 \%$ open. The PRISTINE sampler will therefore be more effectively flushed during deployment than the traditional GOFLO sampler with a $34 \%$ open cross sectional surface area.

\section{The hydraulics system of the PRISTINE sampler}

The hydraulic system to open and close the PRISTINE samplers is completely autonomous and powered by differences in pressure in the water column. It consists of six parts: i) two small PVDF actuating cylinders with internal pistons (attached to the PRISTINE samplers), 
ii) two $175 \mathrm{~mm}$ diameter PVDF seawater inlets with filters to prevent particles to enter the hydraulics system (on top of the frame), iii) the multivalve unit to control the closing of the PRISTINE samplers (de Baar et al., 2008) (in the lower part of the frame), and iv) the pressure accumulator vessel to provide the hydraulic pressure (on the side of the frame) (Figure 3 and 4). The multivalve unit is constructed of poly-oxy-methylene-copolymer (POM$\mathrm{C}$ also known as polyacetal; commercial name Celcon of Celanese Corp.) and contains a titanium enclosed drive motor. The pressure accumulator vessel is constructed of POM-C and contains an internal piston and large stainless steel spring. Note: this stainless steel spring is only in contact with the seawater inside the hydraulics system and not with the environment. All parts of the hydraulic system are connected by polyamide tubing $(8 \times 1 \mathrm{~mm}$; EATON SYNFLEX DIN 73378) and T-joints.

During deployment, the spring in the pressure accumulator vessel gets charged and the pressure accumulator vessel fills with water. Therefore, to prepare the sampling system for deployment the spring in the pressure accumulator vessel needs to be released. The spring gets automatically released by pushing a valve on top of the pressure accumulator vessel which drains the water in the vessel (Figure 4). This allows the spring to push the piston to the top of the pressure accumulator vessel. After that one only needs to close two release plugs in the bottom of the pressure accumulator vessel by pushing them in. Now the system is ready for deployment without having to touch any sampler.

The system is deployed into the ocean and at 5-10 $\mathrm{m}$ depth, the seawater pressure reaches 0.5-1 Bar. This pressure allows seawater entering the system via the seawater inlet on top of the frame to push on the pistons in the actuating cylinders on the PRISTINE samplers, thus opening the lids of the 24 sample bottles. When the pistons of the actuating cylinder reach their maximum positions, the increasing outside seawater pressure (with increasing depth) allows seawater to leak past the lip-seals on the pistons. Passing the lip-seals, the water flows 
via the tubing to the multivalve, where a one-way valve allows the water to pass and flow to simultaneously pushing the piston downwards and charging the internal spring. At 3 Bar overpressure ( 30m depth) the spring is fully compressed and a plastic pipe around the spring will hit the two release plugs that are pushed open, initiating the inflow of seawater from below. This creates equal pressure on both sides of the piston, enabling the spring to create an over pressure of about 2 Bar above the piston.

This 2 Bar over-pressure powers the hydraulic system that closes the lids of the PRISTINE samplers during the up-cast. During the up-cast, at the target depths, PRISTINE samplers are closed in sequence by triggering the multivalve. The multivalve opens the pathway between the pressure accumulator vessel (2 Bar) and the actuating cylinders of the targeted PRISTINE sampler by opening the lever controlled one-way valve for about 8 seconds. This allows seawater to flow on top of the piston in the actuating cylinder thereby pushing the piston downwards and closing the top and bottom lids of the PRISTINE sampler. Small flow restrictions introduced into the top lid hydraulic tubing guarantees that the lower lid always closes first. As a result, the lower lid gets enough time to reach its outermost position, before the upper lid closes too. While closing the lids, the driving force on the actuator cylinders also charges the central titanium lever to its maximum bent position. This 'spring' action will keep exerting an outward pulling force on the lids, thus ensuring them reaching their final positions while the system ascends. The multivalve opens the pathway to the targeted PRISTINE sampler for only 8 seconds to prevent complete depletion of the pressure accumulator vessel reservoir in case one of the individual sampler closure systems should leak, thereby safeguarding the closure of any subsequent samplers. It also prevents samplers that do not close at the targeted depth to close at another depth thereby increasing the integrity of each sample. 
When the CTD system rises further through the water column the outside pressure decreases. A vent valve in the top lid releases the internal over-pressure maintaining a relative overpressure of $+0.5-1$ Bar. The one-way valve in the multivalve maintains an over-pressure of 2 Bar in the tubing and steering cylinder of the closed PRISTINE samplers. At the next target depth the whole procedure is repeated. It is essential to start sampling at the deepest point in the water column. The pressure accumulator vessel contains enough volume of seawater $(6.3 \mathrm{~L})$ to equal the volume in the steering cylinders of the 24 sample bottles three times over (total volume of $2.1 \mathrm{~L}$ ).

\section{The titanium frame, CTD package and PRISTINE samplers - deployment}

To prevent contamination of the trace metal samples, the PRISTINE samplers are mounted on a titanium frame (NIOZ Marine Technology Department) and deployed using a Super Aram hydrowire (Cousin Trestec, France). Most components of the CTD suite are housed in several titanium canisters (Table 1). The Super Aram hydrowire cable is around $9500 \mathrm{~m}$ long, has a diameter of $20 \mathrm{~mm}$ and contains 6 internal copper signal/conductor cables and 1 gel filled stainless steel tube with 4 single mode optic fibres (not used in this set-up). The Super Aram is protected on the outside by an Arnitel plastic jacket.

To prepare for deployment, the only action required is the insertion of two plugs in the bottom of the pressure accumulator vessel, and the release of the remaining seawater atop the internal piston, via the release valve on top of the pressure accumulator vessel. After that, deployment of the titanium CTD system with PRISTINE samplers is the same as described by de Baar et al. (2008). In short, the titanium CTD frame has four wheels used to push the frame out of the clean-air unit onto an aluminum frame on top of a hand forklift. Next, the complete assembly is pushed over the ship's deck to the launching site. From there the frame is lifted over the side and lowered into the sea. At $\sim 30 \mathrm{~m}$ depth all $24 \mathrm{x} 2$ lids of the samplers 
have opened automatically. The complete frame with the open PRISTINE samplers is lowered at a rate of $1.0 \mathrm{~m} \mathrm{~s}^{-1}$ and slower at $0.3 \mathrm{~m} \mathrm{~s}^{-1}$ across steep gradients (e.g. thermocline). Continuous flushing with seawater further cleans the inside of the PRISTINE samplers. The system is typically lowered down until about 20 to $50 \mathrm{~m}$ above the sea floor. The hauling rate during the up-cast can be up to $1.6 \mathrm{~m} \mathrm{~s}^{-1}$, depending on the weather and sea state. During the up-cast, hauling is stopped at each target depth and left for $\sim 60$ seconds to allow a full flushing of the sampler with target seawater before the sampler is closed. The individual PRISTINE samplers are closed by triggering the motor of the multivalve via the CTDcommunication over the hydrowire, just as in a regular CTD-rosette system. Upon return at the sea surface all 24 samplers are firmly closed and the complete frame is taken out of the water. The frame is stabilized using 2 plastic ropes hooked at both sides of the frame before hoisting it carefully back onboard. The frame is lowered and fixed on top of the aluminum frame on the hand forklift. The whole system is then pushed inside the clean-air container and fixed with Ti clamps to the floor of the unit.

Once the exterior door and the interior door are closed, the clean-air circulation is turned on and the team of analysts dress in clean room clothing including Nitrile gloves. Subsampling starts after 5 minutes when the counts of aerosol particles are below requirement as has been shown by tests as described in (de Baar et al., 2008).

\section{Measurements}

Salinity, temperature, nutrients, oxygen, DFe and DAl measurements

We measured salinity, temperature, nutrients, oxygen, dissolved iron (DFe) and dissolved aluminum (DAl) during a test cruise (64PE318) and four cruises in the West Atlantic Ocean (64PE319, 64PE321, 64PE358 and 74JC057) to show the performance of the titanium frame with PRISTINE samplers and CTD system for oceanographic research and 
trace metal clean sampling. Salinities were determined using a SBE3plus thermometer and a a Guildline 8400B Autosal using a P-Series IAPSO Standard Seawater (OSIL, batch P149) to calibrate the salinity measurements of the CTD sensors. The temperature sensor was calibrated against a SBE-35 reference thermometer. The downcast CTD data were binned over a $1 \mathrm{~m}$ interval. Nitrate, phosphate and silicate were determined colorimetrically (Grasshoff et al., 1983) on a SEAL QuAAtro gas-segmented continous flow auto-analyser during 64PE319, 64PE321 and 64PE358 and on a Bran \& Luebbe TrAAcs 800 auto-anlyser during 74JC057. Unfiltered samples were taken from each bottle at each station and analysed on board within 8-12 hours. A natural, sterilized, reference nutrient sample (Kanso, Lot code AX) containing a known concentration of silicate, phosphate, nitrate and nitrite in Pacific Ocean water, was analyzed in triplicate during every run (Table 2). The reproducibility was typically around $0.6 \%$ of the average value for silicate, phosphate and nitrate. There was no significant difference between the shipboard measured values of Kanso and the intercomparison consensus values and therefore, the final sample values were not corrected. Oxygen concentrations were measured using Winkler titrations. The determination of the volumetric dissolved oxygen concentration of water samples was performed colorimetrically by measuring the absorbance of iodine at 460nm on a Hitachi U-1100 Spectrophotometer (Pai et al., 1993). DAl was measured on board using flow injection analysis (FIA) based on a lumogallion fluorometric method (Middag et al., 2011). DFe was measured on board using FIA based on luminol chemiluminescence (Klunder et al., 2011). For both the analysis of DFe and DAl, GEOTRACES and SAFE reference samples were used confirming accurate analysis. The results of the analysis of the reference samples and their consensus values are reported elsewhere (Middag et al., 2015; Rijkenberg et al., 2014). 


\section{Results and discussion}

The closure rate of all 24 PRISTINE samplers during more than 60 deep hydrocasts in the West Atlantic Ocean was $100 \%$, resulting in over 1440 seawater samples from discrete depths. This reliability was confirmed in the 2013 Mediterranean and Black Seas program sampling 76 hydrocasts collecting 1824 samples. Using the PRISTINE samplers on a titanium frame that is transported into a clean-air laboratory unit after recovery saves a lot of time, i.e. bottles do not have to be taken off and returned to the frame and hand-carrying each heavy sampler to and from a clean room is no longer required either. In addition, preparing the system for deployment takes only a couple of minutes as the only actions needed are the manual insertion of two plugs in the pressure accumulator vessel and to press on the release valve on its top. Obviously, the minimal handling is beneficial for cleanliness as well.

We did an intercomparison of the rectangular ultraclean CTD frame with PRISTINE samplers (UCC) and a conventional rosette CTD system with 25L Niskin bottles (ROS) along the West Atlantic transect where we compared CTD sensor data and discrete seawater samples. For both CTD systems salinity and temperature were measured by a SBE-9plus underwater-unit. To prevent a delay in the measurement of the salinity and temperature with depth during the downcast, seawater is pumped through the sensor-unit. We took the $1 \mathrm{~m}$ binned salinity and temperature data of the downcast CTD from both the UCC and the ROS at the same stations and depths and independently calibrated and plotted the ratios $\mathrm{UCC}_{\mathrm{sal}}: \operatorname{ROS}_{\mathrm{sal}}$ and $\mathrm{UCC}_{\mathrm{temp}}: \mathrm{ROS}_{\mathrm{temp}}$ in boxplots (Figure 5a,b). We did the same for UCC:UCC and ROS:ROS at stations where more than one cast was performed with each CTD system to compare for environmental variability. The median of the UCC:ROS ratio of salinity and temperature were both close to 1 and compared well with the median of the UCC:UCC and ROS:ROS of salinity and temperature. This confirms that the ultraclean CTD frame with PRISTINE samplers is providing high quality CTD data. 
Nutrient measurements give a good indication to whether bottles were closed at the right depth and if samples were affected by seawater leakage on the way up through the water column. For this reason, nutrients were routinely sampled from the UCC and the ROS at each station. The UCC:ROS ratio of the nutrients phosphate, nitrate and silicate sampled at the same stations and depths all show median values close to 1 (Figure $5 \mathrm{c}$ ). This indicates that both the PRISTINE and ROS samplers close very well, i.e. once closed there is no contamination due to leakage/exchange with ambient seawater during the up-cast.

Seawater samples taken from the UCC and ROS for the measurement of oxygen show that there is no oxygen exchange between the atmosphere and the seawater inside the PRISTINE samplers (Figure 6). Since only a few seawater samples for oxygen measurements were taken during the casts for calibration of the CTD oxygen sensors, we only have six data points where samples were taken at the same station and depth from both CTD systems. A linear regression through these few data points shows a slope of 1.02 which is very close to 1 considering a standard deviation of $0.85 \mu \mathrm{M}$ over 20 replicate oxygen measurements. There is a small offset with oxygen concentrations of $4.45 \mu \mathrm{M}$ with higher oxygen concentrations in the UCC compared to the ROS. However, this offset may disappear when having more data points over a larger oxygen gradient. If the PRISTINE samplers would not be gas tight we would have expected a slope less close to 1 with more scatter in the data points.

To investigate if the PRISTINE samplers are trace metal clean we performed a test station N-E of Scotland $\left(60^{\circ} 6^{\prime} 0.356^{\prime \prime N}, 5^{\circ} 47^{\prime} 38.76^{\prime \prime W}\right)$ during cruise 64PE318 on RV Pelagia (Gerringa, 2010). We closed all 24 PRISTINE samplers at the same depth near the bottom at $1015 \mathrm{~m}$. The concentrations of DAl were similar in all 24 bottles with an average concentration of $17.41 \pm 0.22 \mathrm{nM}$ (Figure 7a). The concentrations of DFe were very similar in 22 out of 24 bottles with an average concentration of $1.029 \pm 0.045 \mathrm{nM}$ (bottles $2 \& 18$ excluded) (Figure 7b). Since this was the very first time that the PRISTINE samplers were 
used bottles 2 and 18 were apparently not yet entirely clean. Further rinsing of the PRISTINE bottles during subsequent casts removed the contamination from bottles 2 and 18. Overall, this test clearly showed that the PRISTINE samplers are suited for trace metal clean sampling. Additionally, at the Bermuda BATS site $\left(32^{\circ} \mathrm{N}, 64^{\circ} \mathrm{W}\right)$, results of our sampling on $13^{\text {th }}$ of June 2010 show excellent agreement with the crossover occupation on November 19, 2011 by the US GEOTRACES cruise for 13 trace elements as described in the accompanying article of Middag et al. (this issue). Data have been successfully collected (and published) for contamination prone elements like Fe (Rijkenberg et al., 2014), Al (Bruland et al., 2014; Middag et al., 2015; van Hulten et al., 2013), Hg (Lamborg et al., 2014), Co (Dulaquais et al., 2014) and the organic complexation of Fe (Gerringa et al., 2015). This confirms that the intended ultraclean performance of the PRISTINE samplers is excellent.

\section{Conclusions}

The PRISTINE samplers have been extensively used during 4 research cruises in the West Atlantic Ocean (2010-2012). The closing success of all 24 PRISTINE samplers during the more than 60 deep hydrocasts was $100 \%$ resulting in over 1440 seawater samples from discrete depths. Using CTD data from the West Atlantic cruises we show that the UCC CTD data are as good as the ROS CTD data. Investigating the nutrient values between samples taken from the UCC and ROS we conclude that no leakage of the PRISTINE samplers occurred during the up-cast and that therefore samples were indeed from the intended discrete depths. Furthermore, comparing measured oxygen concentrations in seawater samples taken from the UCC and ROS at the same stations and depths show that the PRISTINE samplers are gas tight. Contamination of the seawater samples in the PRISTINE samplers is avoided by keeping samplers always closed when on board. By using the PRISTINE samplers, we completed the GEOTRACES West Atlantic Ocean cruise successfully, determining the 
distribution of a range of contamination prone trace metals along a transect with a length of $17500 \mathrm{~km}$. Overall, the PRISTINE samplers are easy to use, they provide larger sample volumes, they have a $100 \%$ successful closing rate, and their rapid deployment and operation saves ship time. Additionally, there was an excellent agreement of the hydrographic parameters and the major nutrients between the two distinct sampling systems. This all confirms that the new PRISTINE samplers meet the intended requirements.

\section{Acknowledgments}

We express our gratitude to the masters and crews of RV Pelagia and the RRS James Cook for their support during the test cruise 64PE318 and the GEOTRACES GA02 expeditions 64PE319, 64PE321, 64PE358 and 74JC057. We further want to thank Ruud Groenewegen for his suggestions with improving this manuscript. This research is funded by the Netherlands Organization for Scientific Research (NWO) project grant 839.08.410 (GEOTRACES, Global Change and Microbial Oceanography in the West Atlantic Ocean) and project grant 822.01.015 (GEOTRACES, the biogeochemical cycles of bio-essential trace metals and isotopes in the Mediterranean Sea and Black Sea). Information about the sampling system can be requested from the lead engineer Marck Smit (Marck.Smit@ nioz.nl).

\section{References}

Abouchami, W., Galer, S.J.G., de Baar, H.J.W., Alderkamp, A.C., Middag, R., Laan, P., Feldmann, H. and Andreae, M.O., 2011. Modulation of the Southern Ocean cadmium isotope signature by ocean circulation and primary productivity. Earth Planet. Sci. Lett., 305(1-2): 83-91. 
Abouchami, W., Galer, S.J.G., de Baar, H.J.W., Middag, R., Vance, D., Zhao, Y., Klunder, M., Mezger, K., Feldmann, H. and Andreae, M.O., 2014. Biogeochemical cycling of cadmium isotopes in the Southern Ocean along the Zero Meridian. Geochim. Cosmochim. Acta, 127(0): 348-367.

Aoyama, M. and others, 2014. 2012 Interlaboratory Comparison Study of a Reference Material for Nutrients in Seawater. . Technical Report of the Meteorological Research Institute, in press.

Baars, O., Abouchami, W., Galer, S.J.G., Boye, M. and Croot, P.L., 2014. Dissolved cadmium in the Southern Ocean: Distribution, speciation, and relation to phosphate. Limnol. Oceanogr., 59(2): 385-399.

Baars, O. and Croot, P.L., 2011. The speciation of dissolved zinc in the Atlantic sector of the Southern Ocean. Deep Sea Res. II, 58(25-26): 2720-2732.

Bruland, K.W., Franks, R.P., Knauer, G.A. and Martin, J.H., 1979. Sampling and analytical methods for the determination of copper, cadmium, zinc, and nickel at the nanogram per liter level in seawater. Anal. Chim. Acta, 105(1): 233-245.

Bruland, K.W., Middag, R. and Lohan, M.C., 2014. Controls of Trace Metals in Seawater. In: H.D. Holland and K.K. Turekian (Editors), Treatise on Geochemistry. Elsevier, Oxford, pp. 19-51.

Croot, P.L., Baars, O. and Streu, P., 2011. The distribution of dissolved zinc in the Atlantic sector of the Southern Ocean. Deep Sea Res. II, 58(25-26): 2707-2719.

de Baar, H.J.W. and LaRoche, J., 2003. Trace metals in the oceans: evolution, biology and global change. In: G. Wefer, F. Lamy and F. Mantoura (Editors), Marine Science Frontiers for Europe. Springer-Verlag, pp. 79-105.

de Baar, H.J.W., Timmermans, K.R., Laan, P., De Porto, H.H., Ober, S., Blom, J.J., Bakker, M.C., Schilling, J., Sarthou, G., Smit, M.G. and Klunder, M., 2008. Titan: A new 
facility for ultraclean sampling of trace elements and isotopes in the deep oceans in the

Dulaquais, G., Boye, M., Rijkenberg, M.J.A. and Carton, X., 2014. Physical and remineralization processes govern the cobalt distribution in the deep western Atlantic Ocean. Biogeosciences, 11(6): 1561-1580.

Gerringa, L.J.A., 2010. Cruise report: GEOTRACES test cruise. Cruise Report Royal NIOZ. Gerringa, L.J.A., Rijkenberg, M.J.A., Schoemann, V., Laan, P. and de Baar, H.J.W., 2015. Organic speciation of dissolved iron in the West Atlantic Ocean. Mar. Chem.: in press.

Grasshoff, K., Ehrhard, M. and Kremling, K., 1983. Methods of seawater analysis. Verlag Chemie GmbH, Weinheim, 419 pp.

Henderson, G.M. et al., 2007. GEOTRACES - An international study of the global marine biogeochemical cycles of trace elements and their isotopes. Chem. Erde-Geochem., 67(2): 85-131.

Klunder, M.B., Laan, P., De Baar, H.J.W., Neven, I., Middag, R. and Van Ooijen, J., 2014. Dissolved Fe across the Weddell Sea and Drake Passage: impact of DFe on nutrients uptake in the Weddell Sea. Biogeosciences, 10(4): 7433-7489.

Klunder, M.B., Laan, P., Middag, R., De Baar, H.J.W. and van Ooijen, J.C., 2011. Dissolved iron in the Southern Ocean (Atlantic sector). Deep Sea Res. II, 58(25-26): 2678-2694.

Lamborg, C.H., Hammerschmidt, C.R., Bowman, K.L., Swarr, G.J., Munson, K.M., Ohnemus, D.C., Lam, P.J., Heimburger, L.-E., Rijkenberg, M.J.A. and Saito, M.A., 2014. A global ocean inventory of anthropogenic mercury based on water column measurements. Nature, 512(7512): 65-68.

Middag, R., Conway, T., John, S., Bruland, K.W. and de Baar, H.J.W., this issue. Intercomparison of dissolved trace elements at the Bermuda Atlantic Time Series Station. Mar. Chem. 
Middag, R., de Baar, H.J.W., Klunder, M.B. and Laan, P., 2013. Fluxes of dissolved aluminum and manganese to the Weddell Sea and indications for manganese colimitation. Limnol. Oceanogr., 58(1): 287-300.

Middag, R., de Baar, H.J.W., Laan, P. and Bakker, K., 2009. Dissolved aluminium and the silicon cycle in the Arctic Ocean. Mar. Chem., 115(3-4): 176-195.

Middag, R., van Hulten, M.M.P., van Aken, H.M., Rijkenberg, M.J.A., Gerringa, L.J.A., Laan, P. and de Baar, H.J.W., 2015. Dissolved aluminium in the ocean conveyor of the West Atlantic Ocean: Effects of the biological cycle, scavenging, sediment resuspension and hydrography. Mar. Chem.: in press.

Middag, R., van Slooten, C., de Baar, H.J.W. and Laan, P., 2011. Dissolved aluminium in the Southern Ocean. Deep Sea Res. II, 58: 2647-2660.

Morel, F.M.M. and Price, N.M., 2003. The biogeochemical cycles of trace metals in the oceans. Science, 300(5621): 944-947.

Pai, S.C., Gong, G.C. and Liu, K.K., 1993. Determination of dissolved-oxygen in seawater by direct spectrophotometry of total iodine. Mar. Chem., 41(4): 343-351.

Rijkenberg, M.J.A., Middag, R., Laan, P., Gerringa, L.J.A., van Aken, H.M., Schoemann, V., de Jong, J.T.M. and de Baar, H.J.W., 2014. The Distribution of Dissolved Iron in the West Atlantic Ocean. PLoS ONE, 9(6): e101323.

Thuróczy, C.-E., Gerringa, L.J.A., Klunder, M.P., Laan, P., Le Guitton, M. and de Baar, H.J.W., 2011. Distinct trends in the speciation of iron between the shelf seas and the deep basins of the Arctic Ocean. J. Geophys. Res., 116: C10009.

van Hulten, M.M.P., Sterl, A., Tagliabue, A., Dutay, J.C., Gehlen, M., de Baar, H.J.W. and Middag, R., 2013. Aluminium in an ocean general circulation model compared with the West Atlantic Geotraces cruises. J. Mar. Syst., 126(0): 3-23. 
Xue, Z., Rehkämper, M., Horner, T.J., Abouchami, W., Middag, R., van de Flierd, T. and de Baar, H.J.W., 2013. Cadmium isotope variations in the Southern Ocean. Earth Planet. Sci. Lett., 382(0): 161-172.

Zhao, Y., Vance, D., Abouchami, W. and de Baar, H.J.W., 2014. Biogeochemical cycling of zinc and its isotopes in the Southern Ocean. Geochim. Cosmochim. Acta, 125(0): 653672. 
Table 1. The CTD instruments and their housing materials.

\begin{tabular}{|l|l|}
\hline CTD instrument & Housing material \\
\hline Optical BackScatter (OBS) unit & made of rigid polyurethane \\
SBE4 thermometer & titanium housing \\
SBE-5 underwater pump & titanium housing \\
SBE-9plus underwater-unit & titanium housing \\
SBE-43 DO-sensor & titanium housing \\
C-Star Transmissometer & titanium housing \\
& anodized aluminum \\
Chelsea M-III fluorometer & covered with heatshrink plastic \\
Satlantic PAR-sensor & titanium housing \\
Bottom switch & titanium housing \\
\end{tabular}

Table 2. The reference material for nutrients is filtered deep Pacific Ocean seawater (Lot code AX, The General Environment Technos Co., Osaka, Japan). The consensus values are the mean values resulting from an intercomparison exercise of 69 laboratories of the Kanso reference nutrient sample in 2012 (Aoyama and others, 2014).

\begin{tabular}{|c|c|c|}
\hline & $\begin{array}{c}\text { Shipboard value } \\
(\mu \mathrm{mol} / \mathrm{kg})\end{array}$ & $\begin{array}{c}\text { Consensus value } \\
(\mu \mathrm{mol} / \mathrm{kg})\end{array}$ \\
\hline Silicic acid & 59.08 & $59.41(\mathrm{n}=51)$ \\
Nitrate & 21.69 & $21.62(\mathrm{n}=44)$ \\
Phosphate & 1.60 & $01.62(\mathrm{n}=48)$ \\
\hline
\end{tabular}


Figure 1. A schematic drawing and a photograph of a PRISTINE sampler showing the lids (1), the titanium levers (2), and the small PVDF external steering cylinders with internal pistons used to open and close the sampler (3). The ring-shaped top and bottom PVDF end-pieces are welded to the central PVDF pipe (4). The flat silicone O-ring in the closing lids (5). The $135^{\circ}$ angled edge at the inside of end-piece, which serves as the resting surface for the round, flat silicone O-ring in the closing lid (6). Two extensions on the bottom and top end-piece each are used to attach the titanium levers and the steering cylinder to open and close the lids (7) and to attach a small PTFE valve to drain the bottle for sample and pressurize the bottle with $\mathrm{N}_{2}$ gas (8). Furthermore, two PVDF mounting rings are fitted on the outside around the sampler body to fix the PRISTINE sampler to the titanium frame using Ti bolts (9). Lengths are in millimeters.

Figure 2. Schematic drawing of the opening and closing of the samplers by the small PVDF external actuating cylinders with internal pistons (1). On the outside of the lid a rectangular extension block is fitted, with 3 Ti levers attached using small Ti pivoting rods (2). The top lid contains a vent valve in the rectangular extension block allowing the release of trapped air when opening the lids at 5-10 meters below the surface (3). The central Ti lever connects via a Ti vertical rod to the piston in the PVDF cylinder (4). The top lid over-pressure valve allowing water to leave the sampler at $0.5-1$ Bar relative overpressure (5). Top: lid is completely closed; middle: halfway open; bottom: completely opened. Here the effective opening for flushing is $78 \%$ of the cross sectional area defined by the $162 \mathrm{~mm}$ internal diameter of the main pipe.

Figure 3. The titanium frame with the CTD system and the PRISTINE samplers. The two seawater inlets for the hydraulic system are on top of the frame on both sides of the central 
connection of the hydrowire. Each inlet serves 12 samplers (1). The multivalve system is located on the bottom of the frame (2), the pressure accumulator vessel hangs on the side of the frame (3), and the CTD system is implemented on the bottom of the frame (4).

Figure 4. Schematic drawing of the hydraulic system that opens and closes the lids of the PRISTINE samplers. The lids are always closed when on board. After deployment, the lids start to open at 5-10 m depth. The lids are closed again during the up-cast to collect samples. The hydraulic system consists of the two small PVDF actuating cylinders with internal pistons fixed to the PRISTINE samplers (1), two PVDF seawater inlets with filters (2), the multivalve unit (3), and the pressure accumulator vessel to provide the hydraulic pressure (4). The stainless steel spring (5) in the pressure accumulator vessel provides the hydraulic power. The spring is released pressing a valve (6) in the top. Further preparing of the system for a new deployment only requires two release plugs (7) in the bottom of the pressure accumulator vessel to be closed again. The blue arrows (thin arrows) represent the draining of the pressure accumulator vessel after opening of the valve on top of the pressure accumulator vessel before deployment (the lids are closed and stay closed). The green arrows (fatter arrows) represent the pressurizing of the pressure accumulator vessel with increasing depth (the lids are opening). Seawater passes the lip-seals (8) and flows via the one-way valve (9) in the multivalve to the pressure accumulator vessel. Purple arrows (fattest arrows) represent the seawater flow when the lids of the PRISTINE samplers are closed. Triggering the multivalve opens the one-way valve to one of the samplers pressurizing the actuating cylinders and closing the lids.

Figure 5. a) Boxplot showing the ratio in salinity binned per meter measured by the UCC CTD system and the ROS CTD system as well as between multiple casts of the same CTD 
systems at the same stations and depths. b) Boxplot showing the ratio in temperature measured by the UCC CTD system and the ROS CTD system as well as between multiple casts of the same CTD systems at the same stations and depths. c) Boxplot showing the ratio in the nutrients phosphate, nitrate and silicate concentrations as sampled from the UCC and the ROS. Median values are indicated by a horizontal line within the box, the box represents the inter-quartile range, the whiskers extend to the 5th and 95th percentile values, outliers are not shown and $\mathrm{n}$ indicates the amount of data points included.

Figure 6. Oxygen concentrations measured by Winkler titration in discrete samples taken from the UCC and ROS at the same stations and depths.

Figure 7. a.) DAl and b.) DFe concentrations measured in all 24 bottles closed at $1015 \mathrm{~m}$ depth at the test station N-E of Scotland $\left(60^{\circ} 6^{\prime} 0.356^{\prime \prime} \mathrm{N}, 5^{\circ} 47^{\prime} 38.76 " \mathrm{~W}\right)$ during cruise 64PE318 on RV Pelagia. 
Figure 1

Click here to download high resolution image

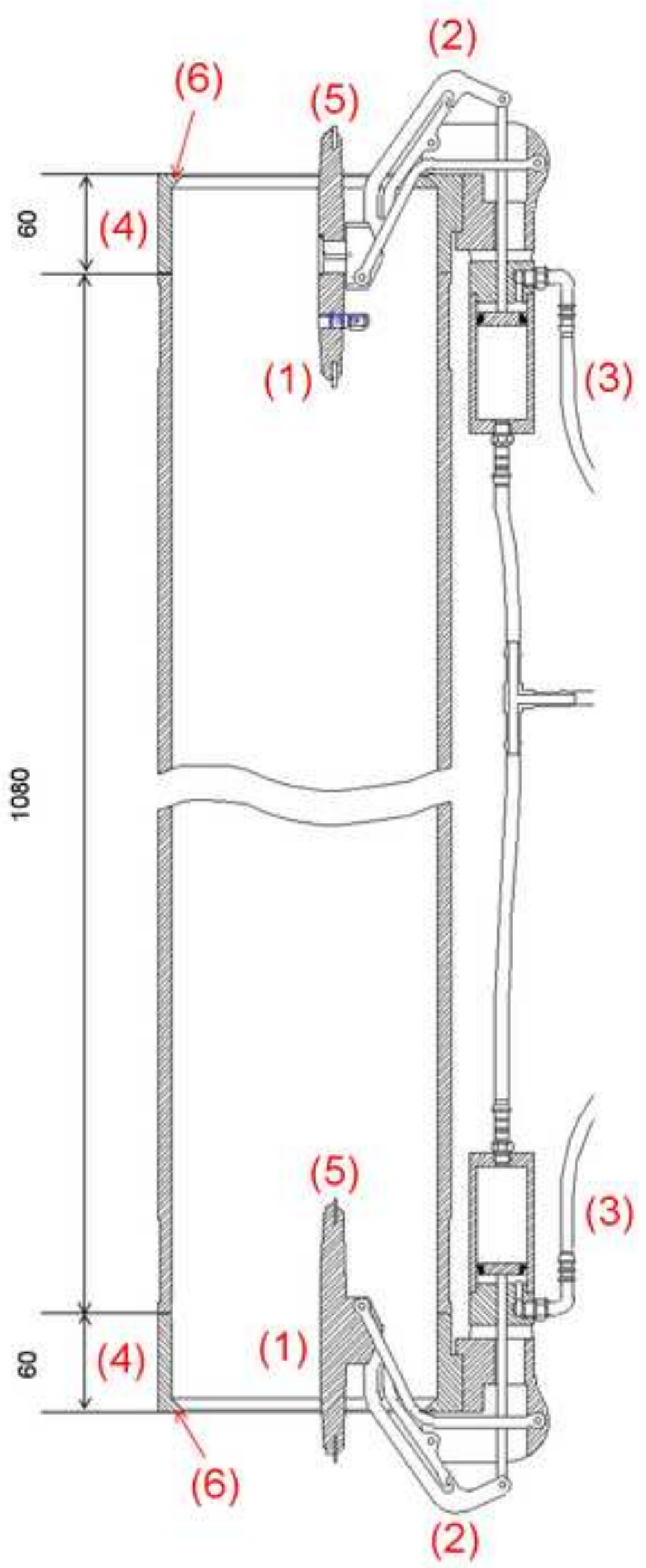

(7)

(8)

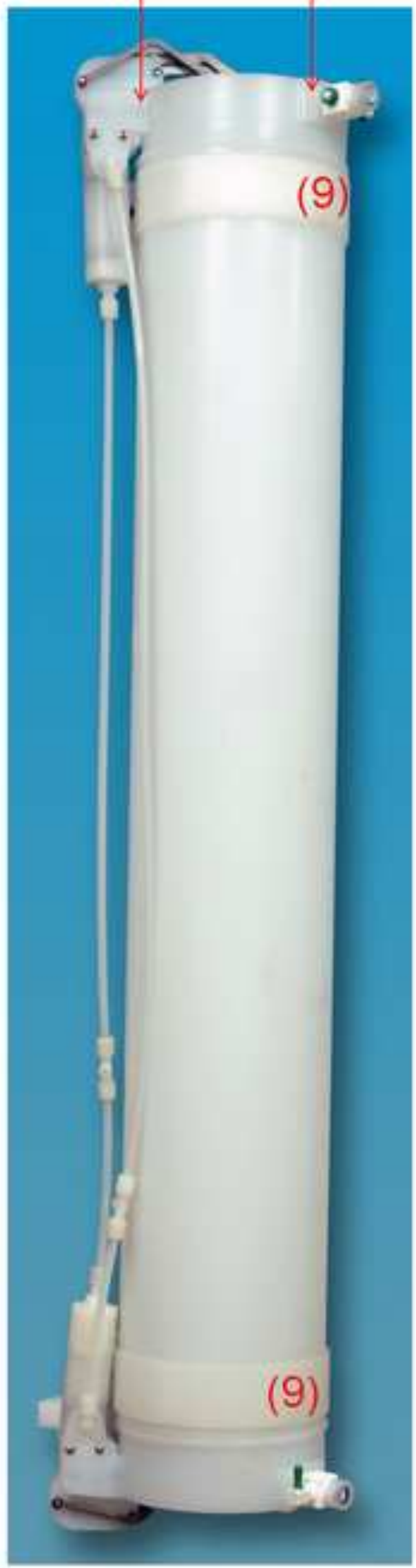

(2) 


\section{Figure 2}

Click here to download high resolution image

cross-section
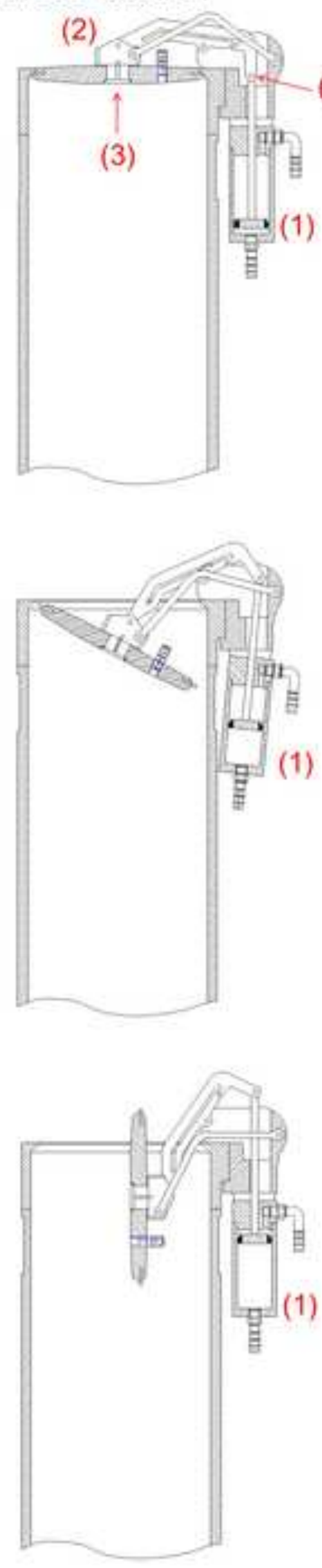

\section{top-view}

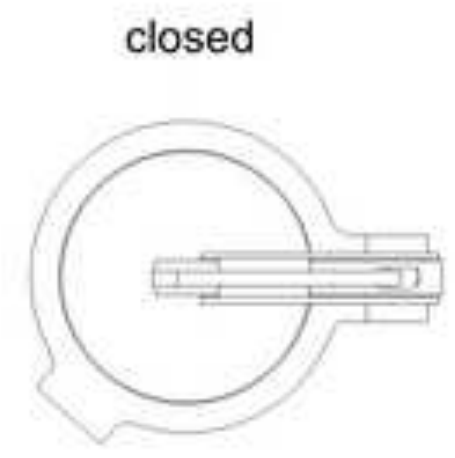

(2) (5)

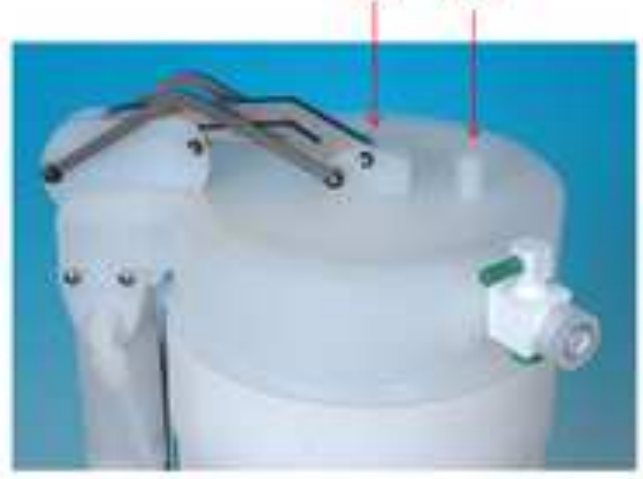

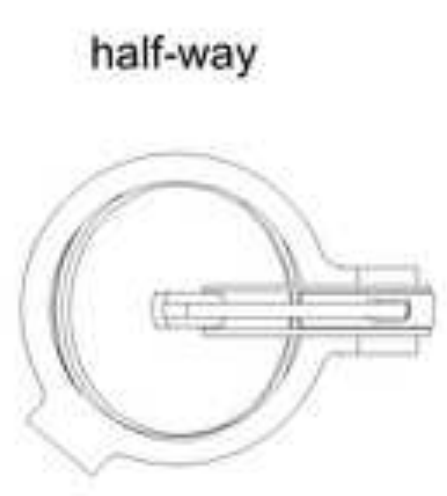
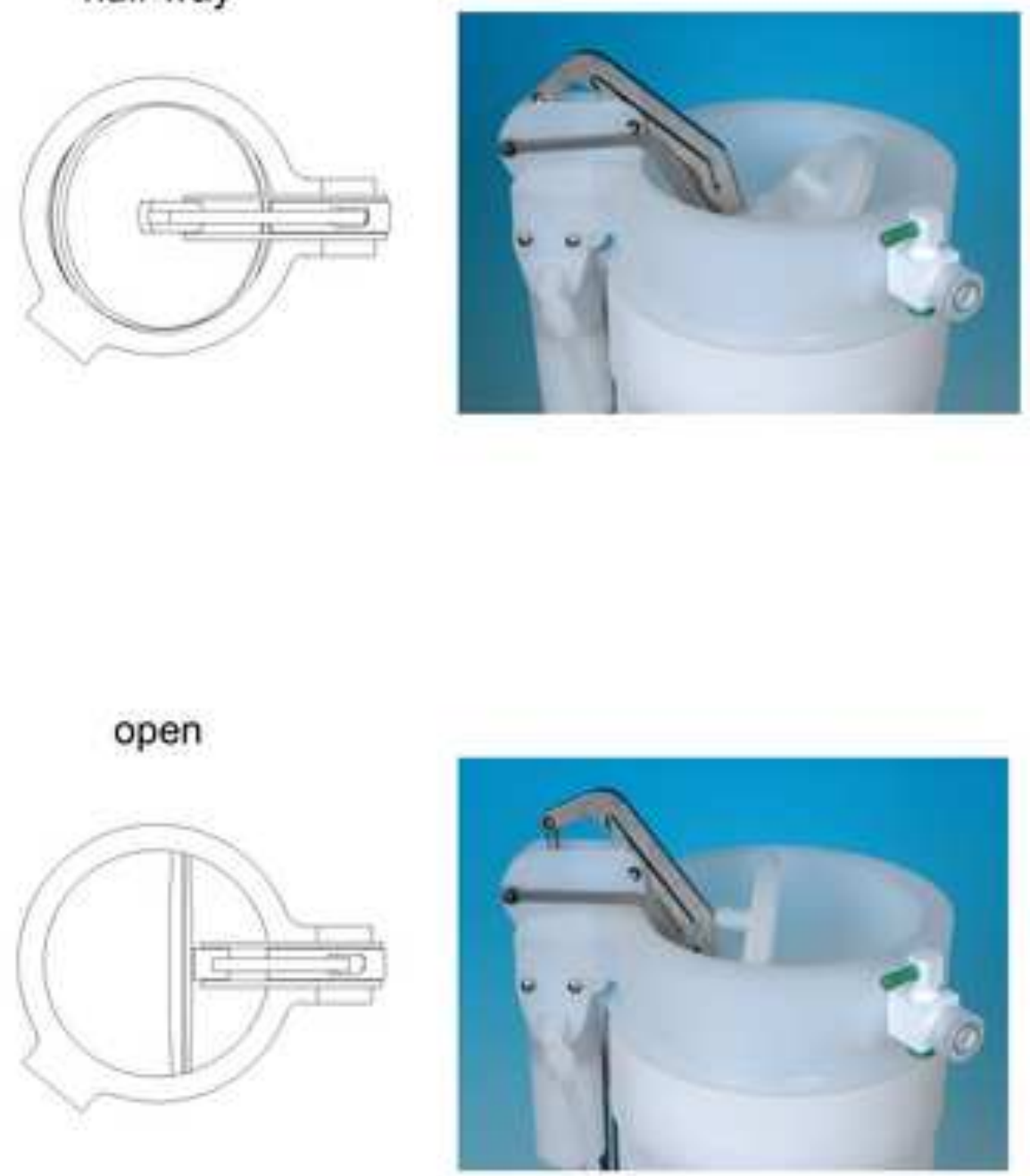
a.

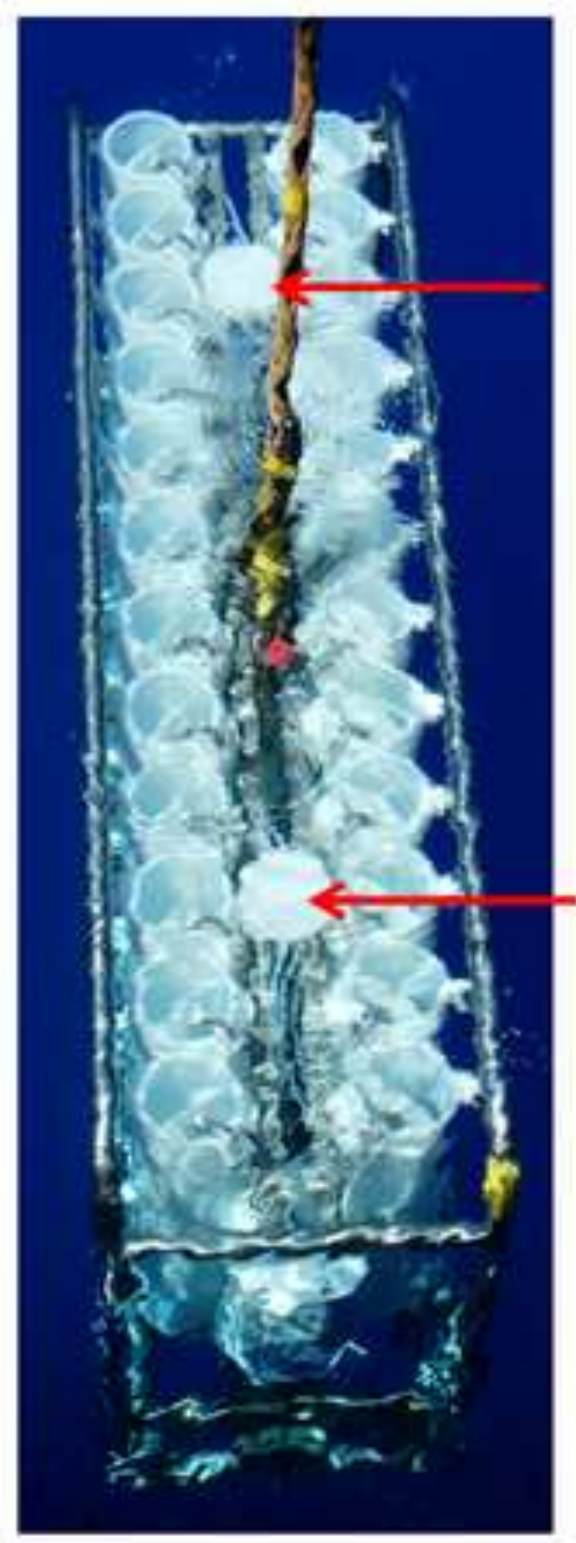

b.

(1)

(1)

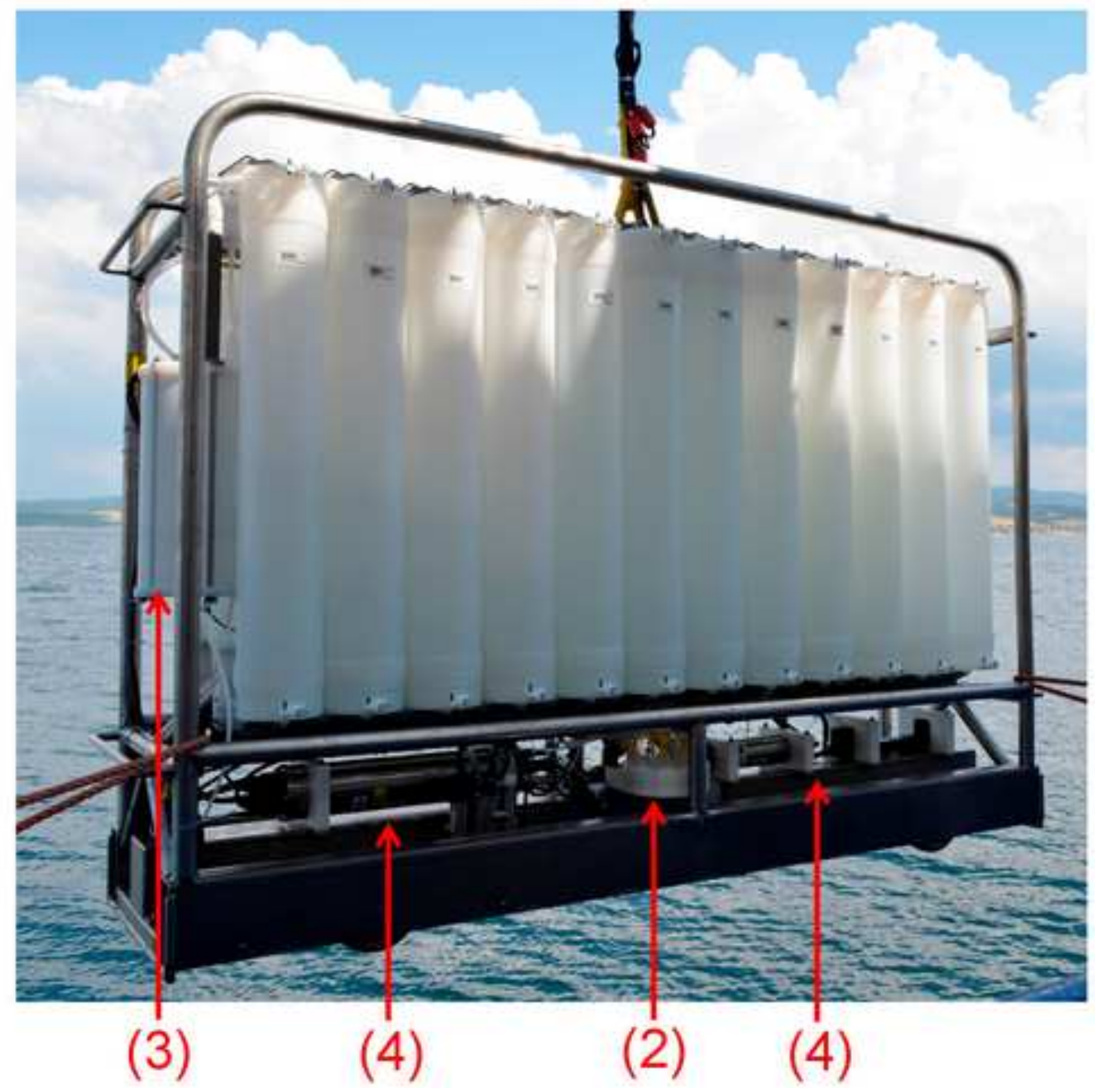


Figure 4.

Click here to download high resolution image

(2)

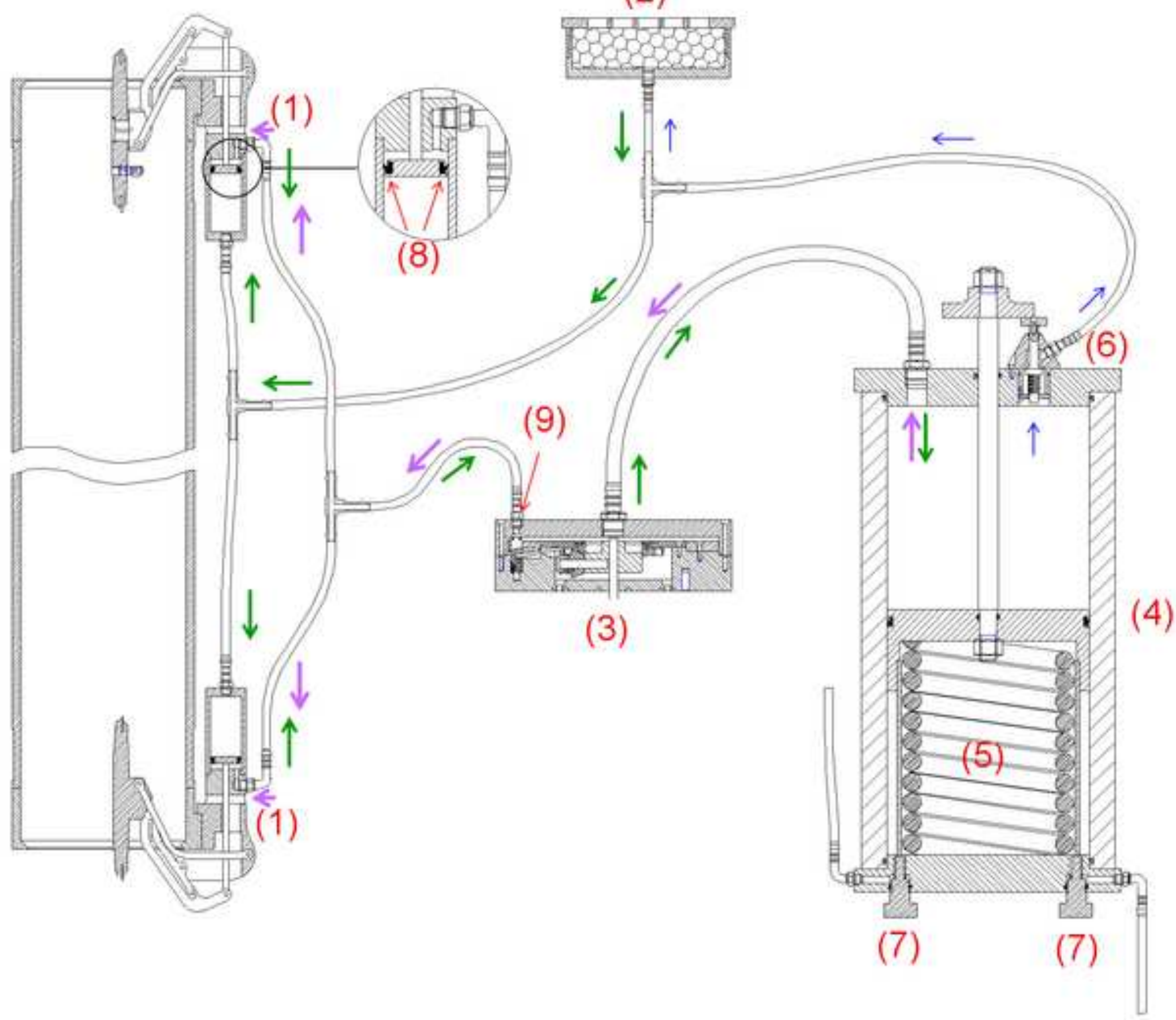


a.

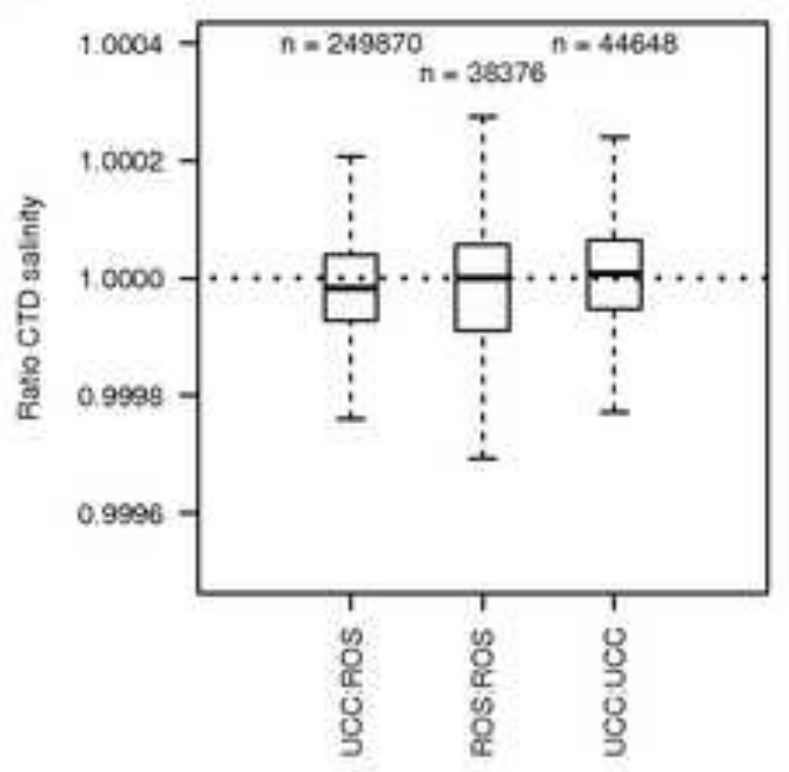

b.

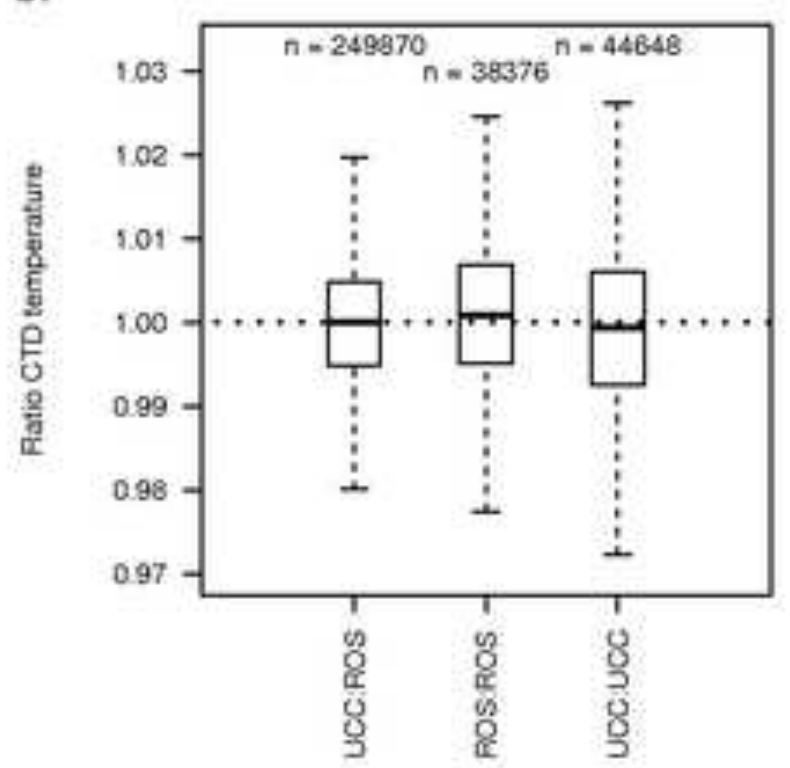

c.

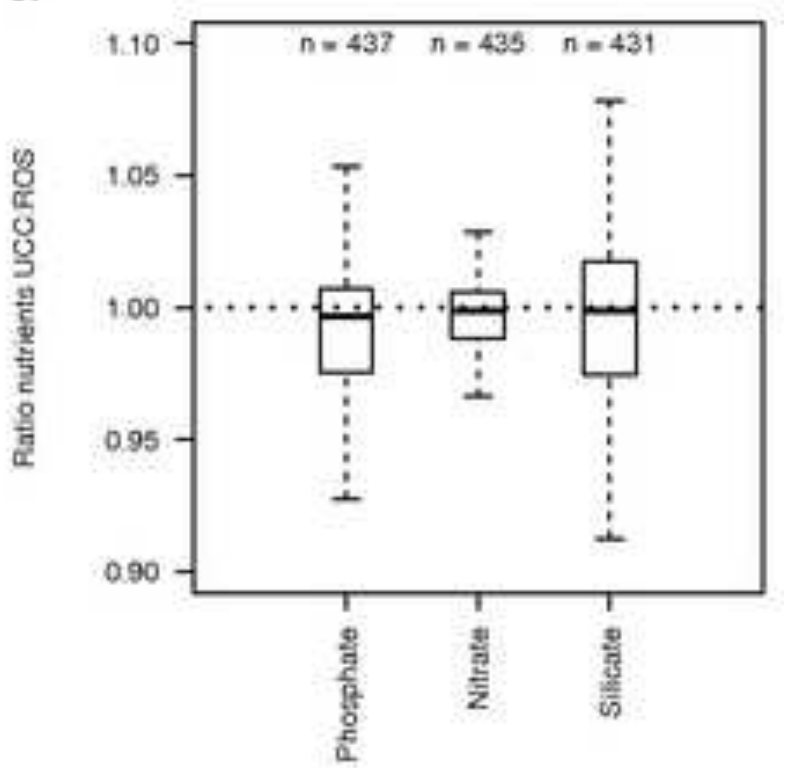




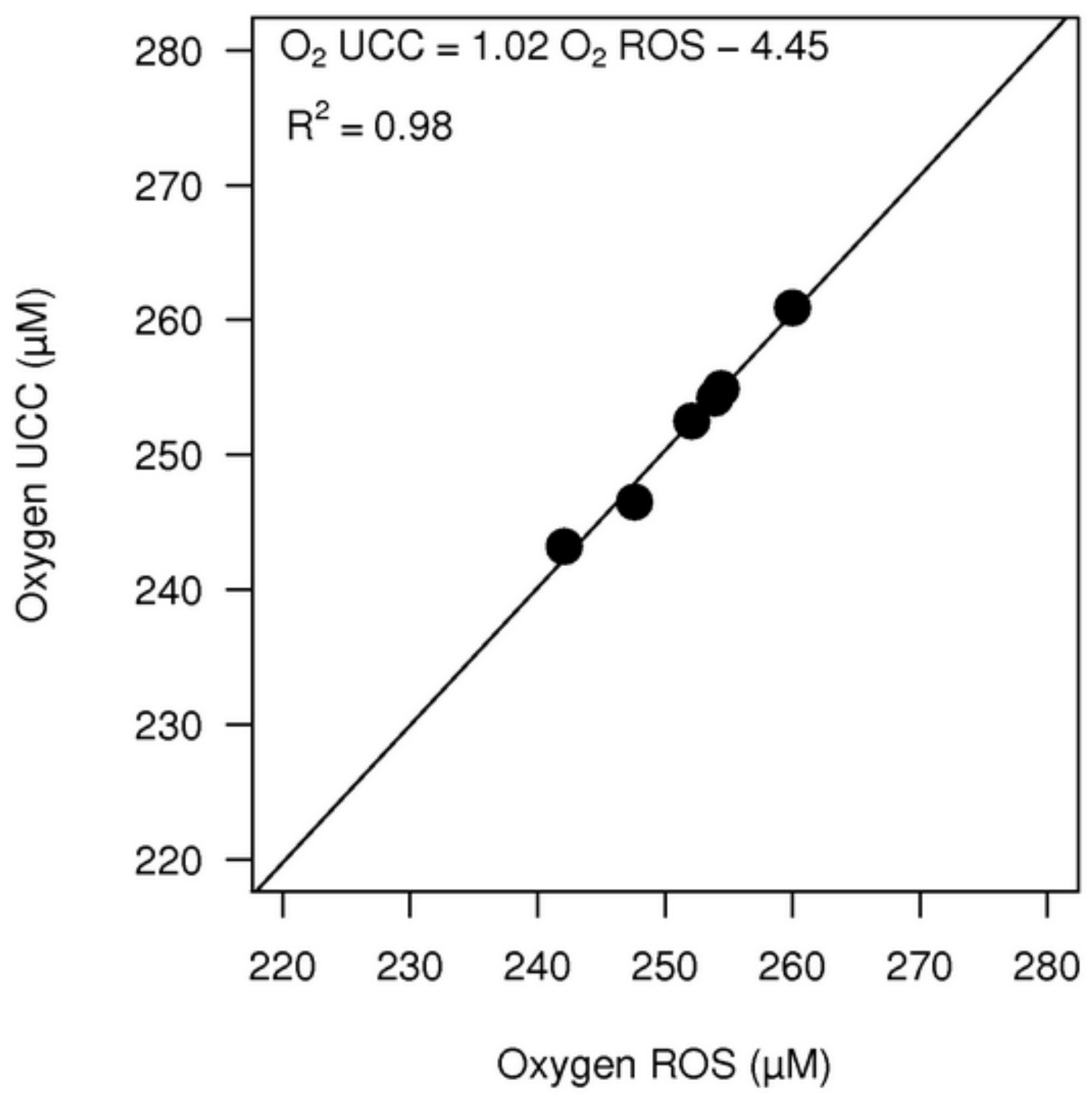


a.

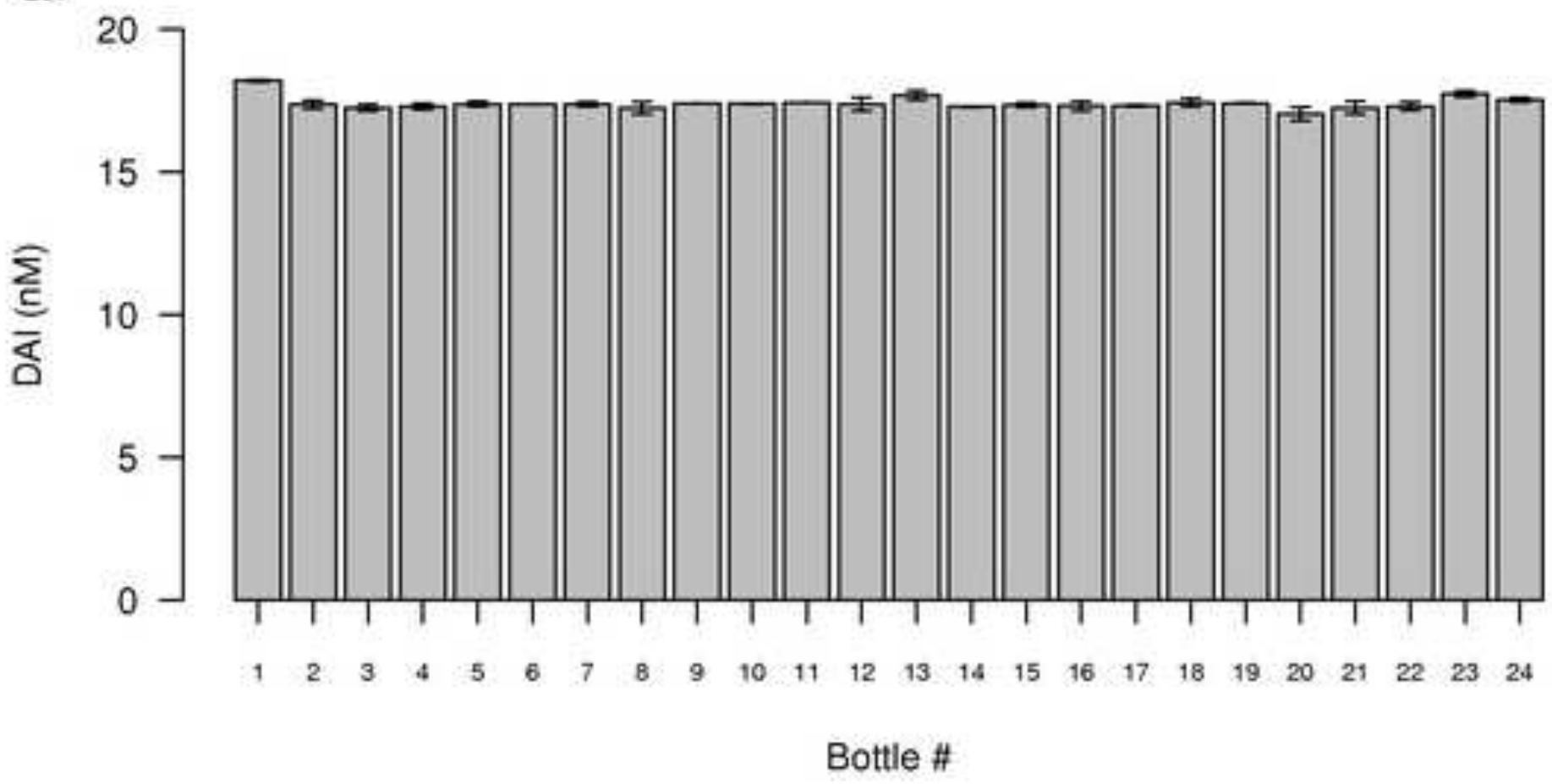

b.

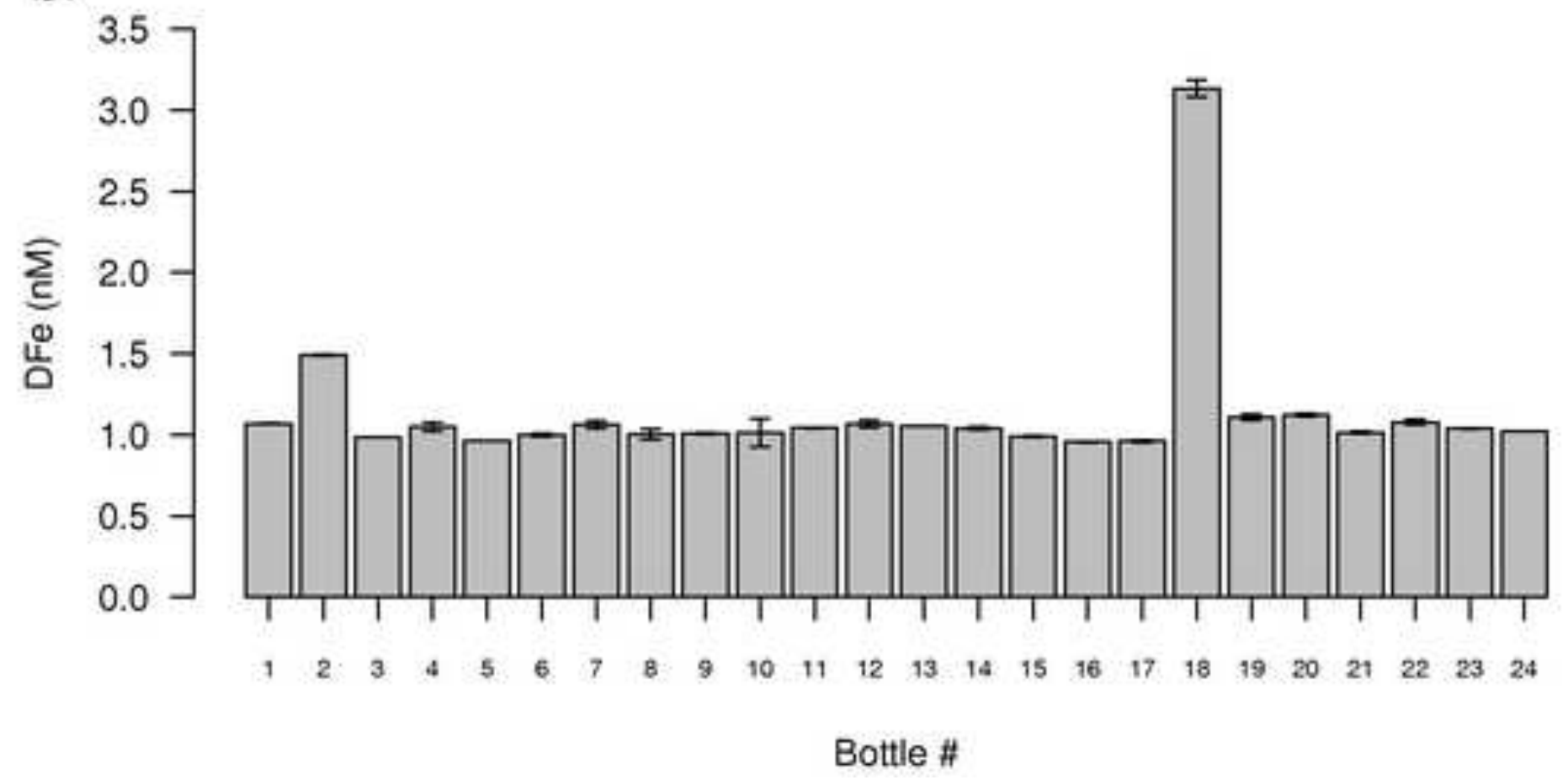

Bottle \# 